\title{
Adrenal Incidentalomas with Review of Literature
}

Shailja Puri ${ }^{*}$, Kavita Mardi $^{2}$, Neelam Gupta ${ }^{2}$ and Manju Rao ${ }^{2}$

${ }^{1}$ Consultant Pathologist \& Lab Head, SRL Ltd, Shimla, Himachal Pradesh, India

${ }^{2}$ Department of Pathology Indira Gandhi Medical College, Shimla, Himachal Pradesh, India

*Corresponding author: Shailja Puri, Consultant Pathologit \& Lab Head SRL Ltd. Shimla, Himachal Pradesh, India, Tel: 91-9459584096; E-mail: drshailjadoe_11@ymail.com

Received date: October 25, 2015; Accepted date: July 20, 2016; Published date: August 01, 2016

Copyright: (c) 2016 Puri S, et al. This is an open-access article distributed under the terms of the Creative Commons Attribution License, which permits unrestricted use, distribution, and reproduction in any medium, provided the original author and source are credited.

\begin{abstract}
Adrenal incidentaloma is a mass lesion greater than $1 \mathrm{~cm}$ in diameter, serendipitously discovered by radiologic examination. The reported incidence of adrenal incidentalomas is between 4-6\%. Majority of reported adrenal incidentalomas are adenomas (hormonally active/inactive), pheochromocytoma, adrenal carcinoma and metastatic carcinomas. We report three rare adrenal incidentalomas with brief review of literature. The three adrenal incidentalomas proved to be adrenal myelolipoma, adrenal pseudocyst and adrenal teratoma on histopathology. Preoperative hormonal assessment and postoperative histopathological examination is required in all cases of adrenal incidentalomas to rule out malignancy.
\end{abstract}

Keywords: Adrenal gland; Incidentaloma; Myelolipoma; Pseudocyst; Teratoma

\section{Introduction}

Adrenal incidentaloma is a mass lesion greater than $1 \mathrm{~cm}$ in diameter, serendipitously discovered by radiologic examination [1]. The entity is the result of technological advances in imaging such as computed tomography (CT), magnetic resonance imaging (MRI) and their widespread use in clinical practice. Numerous autopsy studies have also added to the literature on adrenal incidentaloma. The reported incidence of adrenal incidentaloma is between $4 \%$ to $6 \%$ [1]. We report three rare non-functioning lesions of adrenal gland which were discovered incidentally on performing imaging studies for other with brief review of literature.

\section{Case Reports}

\section{Case 1}

A 52-year-old male presented with incisional hernia in midline abdomen. CT scan of abdomen showed a left adrenal mass measuring $10 \times 7 \mathrm{~cm}$ (Figure 1a). Right adrenalectomy was performed. Grossly, adrenal gland had gray-brown to tan-brown surface. Cut surface showed yellow and tan-brown surface (Figure 1b). Microscopic examination showed tumor composed of mature adipose tissue containing islands of hematopoietic tissue. Hematopoietic component showed trilineage hematopoiesis (Figure 1c). Compressed adrenal tissue was seen towards the periphery. A diagnosis of adrenal myelolipoma was given.

\section{Case 2}

A 32-year-old female presented with right upper abdominal pain. Ultrasonography (USG) of abdomen showed cholelithiasis and left adrenal mass measuring $4 \times 2.5 \mathrm{~cm}$. CT scan showed the adrenal mass to be homogeneous and hypodense. An attempt was made to excise the adrenal mass, however, the cystic mass ruptured in attempt to remove it. Grossly, multiple tan-brown soft tissue pieces were received. Microscopic examination showed a fibrous cyst devoid of any lining (Figure 1d) with areas of dystrophic calcification, hemorrhage, thick walled blood vessels and islands of adrenal cortical tissue. A diagnosis of adrenal pseudocyst was given.

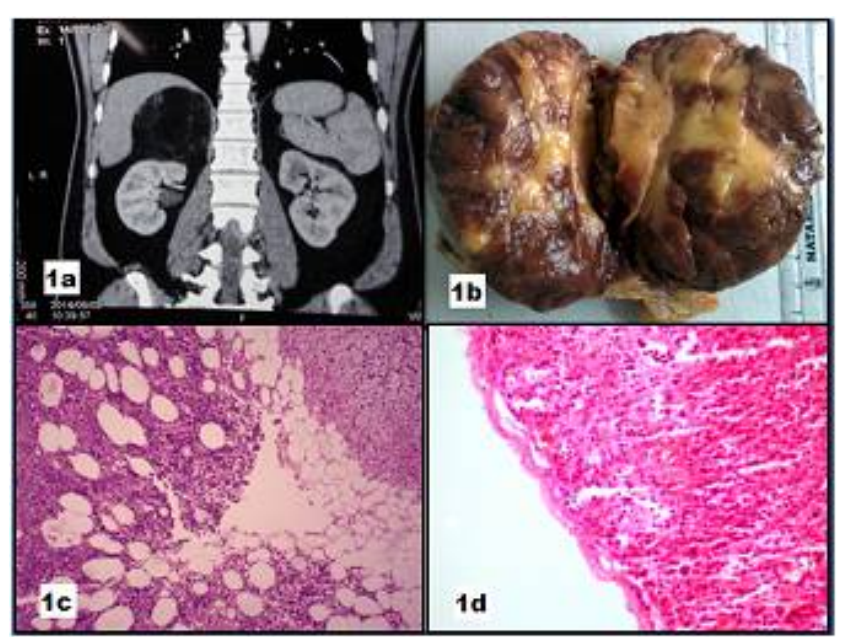

Figure 1: (a) CT scan of abdomen showing a left adrenal mass measuring $10 \times 7 \mathrm{~cm}$ (b) Cut surface of adrenal gland showing yellow and tan-brown surface (c) Microscopic examination showing myelolipoma composed of mature adipose tissue containing islands of hematopoietic tissue with compressed adrenal tissue at the periphery (H\&E, x40) (d) Microscopic examination of adrenal pseudocyst showing a fibrous cyst devoid of any lining (H\&E, x40). 


\section{Case 3}

A 24-year-old female presented with features of acute appendicitispain initially in the umbilical region followed by pain in right lower abdomen. USG showed an adrenal mass. CT scan with contrast showed a right adrenal mass measuring $19 \times 16 \times 9 \mathrm{~cm}$. The mass was multiloculated, containing fat and calcification, suggestive of a adrenal teratoma (Figure 2a). Patient underwent left adrenalectomy and appendicectomy. Grossly, the adrenal mass was multiloculated with smooth tan and shiny surfaces (Figure 2b). Microscopic examination showed cystic spaces lined by keratinizing squamous epithelium along with sebaceous glands, hair, and pancreatic tissue. There were multiple cystic spaces lined by mucous and respiratory epithelium as well as a complete intestinal wall-like structure (Figure $2 \mathrm{c}$ and $2 \mathrm{~d}$ ).

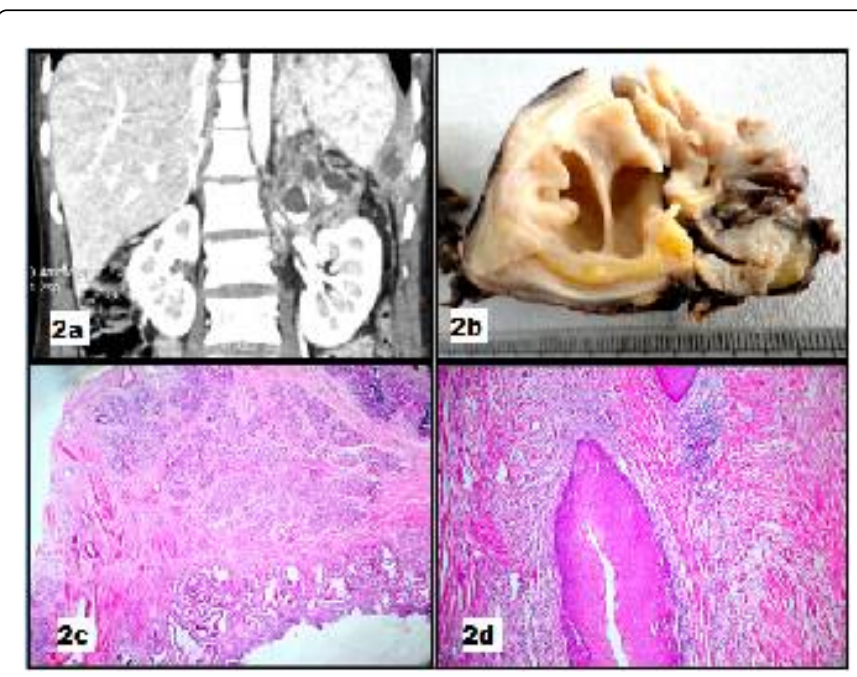

Figure 2: (a) CT scan showing right multiloculated adrenal mass containing fat and calcification, suggestive of a adrenal teratoma (b) Grossly, the adrenal mass was multiloculated with smooth tan and shiny surfaces (c and d) Microscopic examination showed cystic spaces lined by keratinizing squamous epithelium along with sebaceous glands and hair, pancreatic tissue, mucous and respiratory epithelium as well as a complete intestinal wall-like structure.

\section{Discussion}

The reported incidence of adrenal incidentalomas on imaginf studies done for other purposes is 4\% [2] and incidence reported in autopsy studies is 6\% [3]. The prevalance of adrenal incidentaloma increases with increasing age [2]. Majority of adrenal incidentalomas are due to adrenal adenomas, congenital adrenal hyperplasia, pheochromocytoma, adrenal carcinoma and metastatic carcinoma [3]. Majority of adrenal adenomas are non-hypersecreting. The secreting ademonas secrete cortisol, aldosterone and sex hormones, thus hormonal evaluation should be done on detecting an adrenal mass [3]. The possibility of malignant disease is the major concern when evaluating a case of adrenal incidentaloma. A study has shown size of 4 $\mathrm{cm}$ or greater to have greater chance of malignancy [4]. Size is also important because the smaller an adrenocortical carcinoma is at the time of diagnosis, the lower the tumor stage is and the better the overall prognosis will be [5]. Metastases are the cause of the adrenal incidentaloma in approximately half of patients who have a history of malignant disease [6]. Tumors that commonly metastasize to the adrenals include carcinomas of the lung, kidney, colon, breast, esophagus, pancreas, liver, and stomach.

The adrenal incidentalomas that we are reporting are not commonly encountered. We describe each one of them with brief review of literature.

Adrenal myelolipoma is one of 'incidentaloma' which is a clinically inapparent adrenal mass discovered during diagnostic testing or treatment for clinical conditions, not related to the adrenal gland. Adrenal myelolipoma is female predominant disease, mostly asymptomatic, symptomatic lesions can present with abdominal pain and hemorrhage [7]. A fatty adrenal mass is diagnostic of myelolipoma although other less common adrenal tumors containing fat such as teratoma, lipoma, and liposarcoma should be considered [8]. Adrenal myelolipoma can be easily detected on USG, however, CT scan is the most sensitive test for diagnosing myelolipoma. Differentials include adrenal adenoma, adrenal metastasis, primary adrenal malignancy and retroperitoneal lipoma and liposarcoma [7]. Adrenal myelolipoma can co-exist with other adrenal tumors like adrenocortical adenomas and adenomatoid tumors of the adrenal gland [9].

Besides other adrenal tumors, myelolipoma has been found to be associated with endocrine disorders, adrenal dysfunction and hyperstimulation with adrenocortocitrophic hormone. A case of adrenal myelolipoma has been described with chromosomal translocation $(3 ; 12)(\mathrm{q} 25 ; \mathrm{p} 11)$ indicating that it is bona-fide neoplasm [10].

Adrenal pseudocysts are rare and represent $80 \%$ of cystic masses of adrenal [11]. Two types of cysts are known to occur in adrenal glandendothelial cyst and hemorrhagic or pseudocyst. Microscopically, both cysts are lined by partially calcified wall without an epithelial lining. Endothelial cyst is filled with serous fluid while hemorrhagic or pseudocyst is filled with clotted blood or hyalinized thrombus with attenuated adrenal cortex [12]. The exact pathogenesis of adrenal cysts is not known, however, vascular anomaly, perhaps of lymphatic nature in former and blood vessel type in the latter has been suggested [12]. Adrenal pseudocysts present with symptoms associated with large tumor size, hypertension, infection or shock due to hemorrhage [12]. Pseudocysts may be isolated or associated with a primary adrenal neoplasm, such as pheochromocytoma, adrenocortical carcinoma, adrenocortical adenoma, or neuroblastoma [13]. Differential diagnosis of adrenal pseudocyst includes endothelial cyst, epithelial cyst, lymphangioma and parasitic (hydatid) cyst.

Adrenal gland as the site of teratoma is extremely rare. Adrenal teratomas have no specific clinical manifestations. They are often found incidentally on USG. However, abdominal distension, abdominal pain, low back pain, intestinal obstruction caused by compression of the neoplasm can occur in one half of patients [14]. The diagnosis of adrenal teratoma relies predominantly on an imaging examination. Plain abdominal film shows calcification. USG and CT scan identify the cystic, solid or complex components of the tumor [15]. MRI is better than USG and CT to demonstrate the anatomical relationship [15]. The differential diagnosis of retroperitoneal teratomas include ovarian tumors, renal cysts, adrenal tumors, retroperitoneal fibromas, sarcomas, hemangiomas, xantogranuloma, enlarged lymph nodes and perirenal abscess [14]. A postoperative pathologic examination has often been required for a definitive diagnosis. 
Citation: Puri S, Mardi K, Gupta N, Rao M (2016) Adrenal Incidentalomas with Review of Literature. J Cytol Histol 7: 426. doi: 10.4172/2157-7099.1000426

Page 3 of 3

\section{References}

1. Young WF Jr (2007) Clinical practice. The incidentally discovered adrenal mass. N Engl J Med 356: 601-610

2. Bovio S, Cataldi A, Reimondo G, Sperone P, Novello S, et al. (2006) Prevalence of adrenal incidentaloma in a contemporary computerized tomography series. J Endocrinol Invest 29: 298-302.

3. Young WF Jr (2009) Management approaches to adrenal incidentalomas: a view from Rochester, Minnesota. Endocrinol Metab Clin North Am 29: 159-185.

4. Angeli A, Osella G, Ali A, Terzolo M (1997) Adrenal incidentaloma: an overview of clinical and epidemiological data from the National Italian Study Group. Horm Res 47: 279-283.

5. Allolio B, Fassnacht M (2006) Adrenocortical carcinoma: clinical update. J Clin Endocrinol Metabb 91: 2027-2037.

6. Lenert JT, Barnett CC Jr, Kudelka AP, Sellin RV, Gagel RF, et al. (2001) Evaluation and surgical resection of adrenal masses in patients with a history of extra-adrenal malignancy. Surgery 130: 1060-1067.

7. Han M, Burnett AL, Fishman EK, Marshall FF (1997) The natural history and treatment of adrenal myelolipoma. J Urol 157: 1213-1216.
8. Daneshmand S, Quek ML (2006) Adrenal myelolipoma: Diagnosis and management. Urology Journal 3: 71-74.

9. Timonera ER, Paiva ME, Manuel LJ, Catarina E (2008) Composite Adenomatoid Tumour and Myelolipoma of adrenal gland: Report of 2 cases. Arch Path Lab 132: 265-267.

10. Chang KC, Chen PI, Huang ZH, Lin YM, Kuo PL (2002) Adrenal myelolipoma with translocation $(3 ; 21)(\mathrm{q} 25 ; \mathrm{p} 11)$ Cancer Genetics 134 : 77-80.

11. Erickson LA, Lloyd RV, Hartman R, Thompson G (2004) Cystic adrenal neoplasms. Cancer 101: 1537-1544.

12. Rosia J, Ackerman LV (2011) Adrenal gland and other paraganglia. In: Ackerman LV (ed.) Rosia and Ackerman's Surgical Pathology (10thedn) New Delhi: Elsevier, p: 1139.

13. Habra MA, Feig BW, Waguespack SG (2013) Adrenal pseudocyst. The Journal of Clinical Endocrinology and Metabolism 90: 3067-8.

14. Ciftci I, Cihan T, Koksal Y, Ugras S, Erol C (2013) Giant Mature Adrenal Cystic Teratoma in an Infant. Acta Inform Med 21: 140-1.

15. Wootton-Gorges SL, Thomas KB, Harned RK, Wu SR, Stein-Wexler R, et al. (2005) Giant cystic abdominal masses in children. Pediatr Radiol 35: 1277-1288. 